\title{
Indigenous Practices of Ganta Community in Protecting Natural Resources, Gamo Gofa Zone, Ethiopia
}

\author{
Daniel Shiferaw $^{1}$, Serekebirhan Takele ${ }^{2, *}$, Alemayehu Hailemichael ${ }^{2}$ \\ ${ }^{1}$ Project Concern International (PCI), Robe, Ethiopia \\ ${ }^{2}$ Department of Biology, Arba Minch University, Arba Minch, Ethiopia
}

Email address:

dan_dinsa@yahoo.com (D. Shiferaw), serekebirhan.takele@amu.edu.et (S. Takele), alemayehu.hailemichael@amu.edu.et (A. Hailemichael) ${ }^{*}$ Corresponding Author

\section{To cite this article:}

Daniel Shiferaw, Serekebirhan Takele, Alemayehu Hailemichael. Indigenous Practices of Ganta Community in Protecting Natural Resources, Gamo Gofa Zone, Ethiopia. International Journal of Environmental Protection and Policy. Vol. 5, No. 5, 2017, pp. 74-83.

doi: $10.11648 /$ j.ijepp.20170505.12

Received: November 27, 2016; Accepted: June 26, 2017; Published: November 30, 2017

\begin{abstract}
Indigenous knowledge (IK) is a knowledge that people in a given community has developed over time, and continues to develop. IK on environment contributes to sustain ecosystem services and to mitigate climate change. The study explored the role of indigenous practices in protecting natural resource around Arba Minch ZuriaWoreda of ZigityKebeles. It used perception of people on the role of indigenous practices in natural resources management and environment protection using structured and non-structured questionnaires, focused group discussions with key informant and interview of 143 individuals. Data on ecological knowledge was collected from 12 sample villages with 40 key informants. Accordingly, 75\% of the respondents agreed that the communities are not using indigenous practices for natural resources management in their area development program. Similarly, $76 \%$ of the respondents agreed that there was little support from government, and other institutions on traditional knowledge capacity building. However, indigenous practices of traditional land management have existed as the part of Ganta community and this was reflected by different local terminologies, proverbs, and sayings. There is a well-structured traditional institution that benefits the conservation of natural resources. The study recommended that traditional practices of the community have to be fully applied in natural resource management strategies of any development program in the area. Integrating the local knowledge to work with the existing social institutions will increases the efficiency of natural resources management system.
\end{abstract}

Keywords: Indigenous Knowledge, Traditional Practice, Natural Resources Management, Environment, Ecological Knowledge

\section{Introduction}

The study of indigenous knowledge (IK) in society and community has become an important subject of inquiry, for development. It is gaining increased attention and its' importance in sustainable development is well-recognized (Warren and Rajasekaran, 1993). The term local or indigenous knowledge is used to distinguish the knowledge developed by a given community from international knowledge systems or scientific knowledge (Kolawole, 2001; Herweg, 2002; Ajibade, 2003; Tripathi and Bhattarya, 2004). Indigenous knowledge provides the basis for problemsolving strategies for local communities. In various places of the world, scientists and indigenous people are collaborating to build bridges between modern science and indigenous knowledge to improve ecological management of a particular region and it is a component of knowledge on development issues (Reijntjes, 2004).

IK is highly associated with land management in Ethiopia. Ethiopian farmers have been aware of the problems of soil degradation. Traditionally they are conservation minded at the level of the farm. Adaptive measures for agriculture range from technological solutions to farm management and political changes such as adaptation plan (Brussel, 2009). Local knowledge is an underutilized resource in the development process of Ethiopia. However, policy makers and agricultural development planners are beginning to recognize indigenous 
knowledge systems and have shown renewed interest in local knowledge (Warren and Rajasekaran, 1993). A global network of indigenous knowledge for natural resources management and the importance to integrate into contemporary conservation and sustainable management of natural resources has also been studied (Rist and Dahdouh, 2006). Indigenous knowledge systems in land management have played a vital role in ecosystem management for generations in Ethiopia. There are some practices of using traditional knowledge to manage soil. The protection of soils by crop residue is wildly used in Damot-Sore (Walayita area) by the communities (Abebe et al., 2011).

Incorporating indigenous knowledge into existing scientific knowledge can contribute to local empowerment and development, increasing self-sufficiency and strengthening self-determination. Utilizing indigenous knowledge in management plans gives legitimacy and credibility in the eyes of both local people and outside scientists, increasing cultural pride and thus motivation to solve local problems with local ingenuity and resources (Thrupp, 1998).

In Zigity kebeles, there is severe soil degradation, deforestation, and poor agricultural practice and land slide. Indigenous knowledge are threatened with less consideration by development agents over which the community participation is trivial. The local knowledge is undermined by the existing development approach mainly in natural resources management and for mitigation of the rapidly changing natural environments. The repercussions of the disturbances on the indigenous knowledge are not realized by development actors so far. Hence, it is towards this end that the present study reveals the role of indigenous knowledge in protecting the environment.

\section{Methods}

\subsection{Description of the Study Area}

The Southern Nation Nationalities and Peoples' Region (SNNPR) has 17,359008 million people with more than 50 different ethnic groups (CSA, 2016). Gamo-Gofa zone has a total area of 12581.4 square kilometre and consists 15 woredas (ArbaMinchZuriaWoreda Administration Office, 2015). The general elevation of the zone ranges from 600 to 3300 meters above sea level (ArbaMinchZuriaWoreda Administration Office, 2015). The topography and altitude of the land characterizes an undulating feature that favors for the existence of different climatic zones in the area. The total population of the zone is estimated to 1,597767 with a population density of 80 inhabitants per kilometre square. Arba Minch Zuriaworeda comprises 29 kebeles that surround the GamoGofa Zone and the capital town is Arba Minch (Figure 1). ArbaMinch town is the administrative and trading center of the zone, located at $505 \mathrm{~km}$ a way from Addis Ababa and $275 \mathrm{~km}$ south west of Awassa.

Traditional crop rotation, intercropping and livestock rearing system are the predominant farming system in the study area. The main crops grown in the study area are; Barely (Hordeumvulgare) and wheat (Triticumspp) in the higher altitude and Sorghum is produced in the low land areas. In addition to land management practices for improving crop land productivity, majority of the farmers except a few farmers who use shifting cultivation at low land areas, are using inorganic fertilizers for soil fertility enhancement. DAP and UREA fertilizers are widely used. Oxen are used for ploughing land. The human labour is used for ploughing mountainous area. Hand weeding is common for the farmers and herbicide use is not familiar. Some perennial crops like Coffee, Banana and Mango are also grown in the low land areas. Rainfall is the main source of water for agriculture in the area. The population density is high and the average land holding is estimated to be 0.25 hector per household. Agro-forestry is one of the practices mainly well integrated with the cultivated crops and considered as an important component of the farm. A few farmers continue this practice, but the practice is still very much in progress (ArbaMinchZuriaWoreda Administration Office, 2015).

\subsection{Study Design}

The study design was based on structured questionnaire and pilot survey. Study population was Zigitykebeles population. Stratified random sampling technique was used. The technique partitions the sample frame into non-over lapping and relatively homogenous groups - strata. The selection of samples was then undertaken independently in each stratum. The villages in the kebeles (Peasant Association) were selected using simple random sampling technique. To measure the ecological knowledge, purposive sampling was used with key informants.

\subsection{Description of Study Subjects}

The indigenous practices were studied at community level and the benefits were described for natural resources management and environmental protection. The indigenous knowledge holders' and inhabitants of the area participated in providing information through interview and focused group discussion, respectively. Culture and existing tradition of the community were taken in to consideration that proverbs and saying of the community elicited from elders.

\subsection{Sample Size and Sampling Procedure}

The sample size determination was dependent on the population size of each kebele and the response given to the main response variable. Thus, for sample size determination stratified sampling was used by the pilot survey. The main response variable was taken for responding in yes and no question. This method was used as it reduced sampling error and separate estimate are required at stratum level. The sample size estimation of the population proportion " $\mathrm{P}$ " in the Zigity Kebeles for the allocation of the overall sample was obtained following Roscoe (1975). 


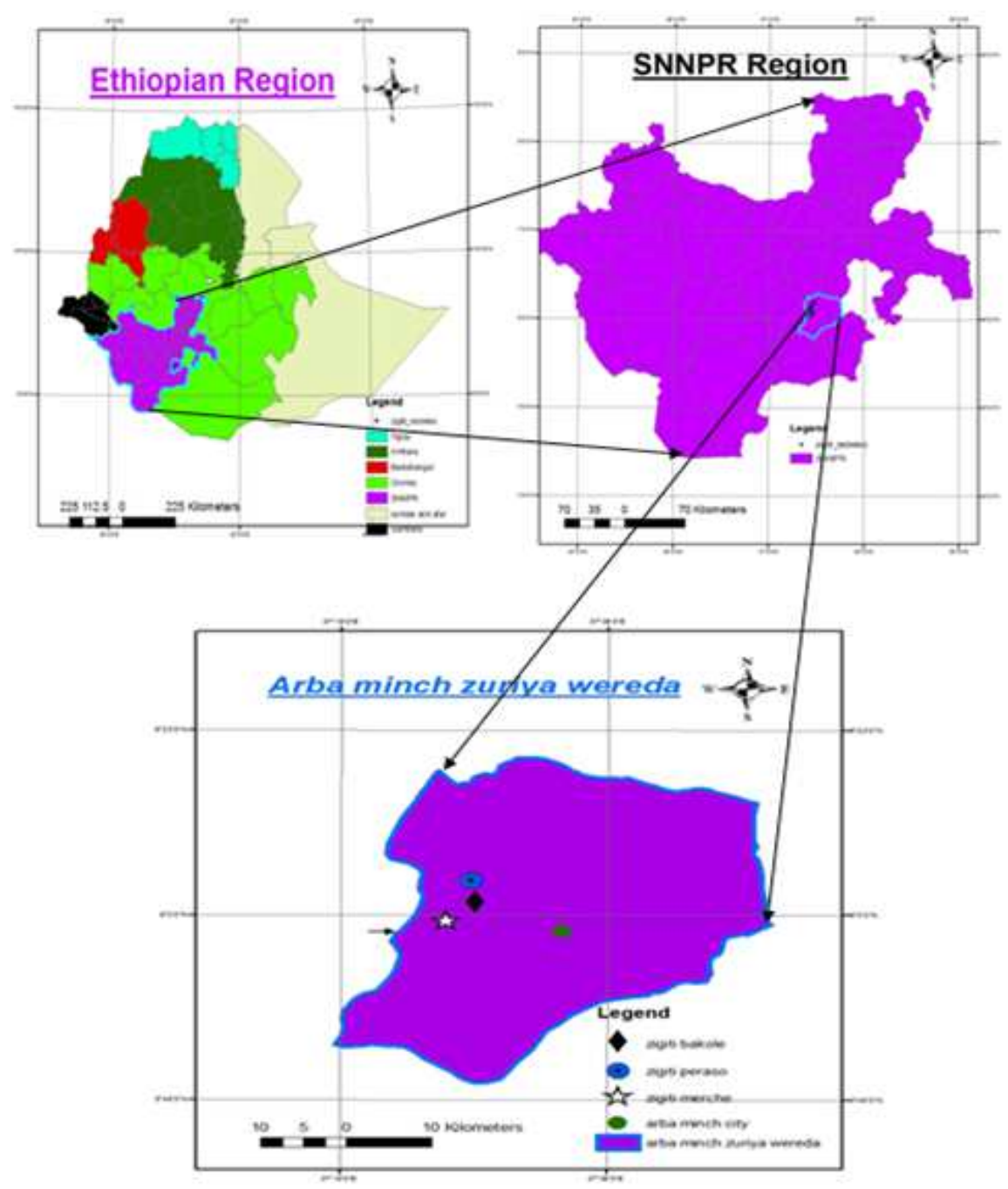

Figure 1. Map of the Study Area.

\subsection{Method of Data Collection}

Both primary and secondary data were collected. Primary data sources were the respondents in the study area that was collected by questionnaires, focus-group discussions, field observation and intensive interviews with 143 sample farmers, and other key informants including zonal and local government officials, development agents. Secondary data was collected from concerned offices, journals and reports.

\subsection{Data Collection Tools}

Different data collection instruments were used to conduct the study. Series of questions and other prompts for the purpose of gathering the information from respondents were used as a questionnaire which consists of both open and closed ended questions. Interviews, focus group discussion and observation were also employed.

\subsection{Strategies of Ensuring Data Quality}

To maintain data quality, questionnaires were pre tested before the actual survey commenced. Three development agents who are working in the study area were facilitating and participating in data collection. They used local language to communicate the community with the translated questioner. People with traditional knowledge were interviewed and their voice was recorded.

\subsection{Description of Materials and Procedure}

Besides questionnaires and interviews, other different data collection materials such as digital camera, video camera, and voice recorder were used. Participatory Rural Appraisal methods such as focused group discussion, wealth ranking, key informant discussions were applied. Perception of people on the role of indigenous knowledge in natural resources management and environment protection were gathered using focused group discussion with key informant. Ecological knowledge was collected from sample of 12 villages in the Peasants Associations (PA) with 40 key informants deliberately chosen because of their rich experience on natural resources management as identified by elders, local administrators and office of agriculture staff. 
As a follow up of the discussions with key informants, successive interviews and discussions were held in the villages with an average of seven community members involving elders, men, women and youth. Expert rating was used to show role of indigenous practices used as indicated in Liniger and Critchley (2007).

\subsection{Data Analysis}

The collected data was analyzed using statistical SPSS (statistical package for social Sciences) version 20. Figures, tables, and charts were used to describe the data. Furthermore, the data was analyzed from the perspective of social institution and natural resources management strategies. Traditional ecological knowledge (TEK) and scientific ecological knowledge (SEK) were examined qualitatively in indigenous natural resources management and environment protection.

\section{Results}

\subsection{The Role of Indigenous Knowledge in Protecting Natural Resources}

In Ganta community culture, it is the responsibility of every individual to protect natural resources. During the study, $86 \%$ of the respondents agreed that, men women, youth, and elders involved in protecting the natural resources. However, the communities depend more on their elders to protect the environment and natural resources than the youth, and women's. It was revealed from the respondents (80\%) that different traditional activities are commonly practiced by the Ganta community (Table 1).

Table 1. List of selected Indigenous Practices in agricultural activities of Ganta Community.

\begin{tabular}{|c|c|c|}
\hline Local names & English terms & Descriptions of the Indigenous Agricultural Practices \\
\hline Osha & $\begin{array}{l}\text { Manure making for } \\
\text { soil fertility }\end{array}$ & $\begin{array}{l}\text { This was the most common agricultural practice in the area for improving soil fertility. The majority } \\
(88 \%) \text { of the farmers practiced manure making for soil fertility. }\end{array}$ \\
\hline IgisseAreda & $\begin{array}{l}\text { Compost making for } \\
\text { soil }\end{array}$ & $\begin{array}{l}\text { This was less practiced by the farmers but government agricultural workers encourage the farmers } \\
\text { to use compost }\end{array}$ \\
\hline $\begin{array}{l}\text { Hapa /Kalle Gosha } \\
\text { Gadena Agoo }\end{array}$ & Leaving crop residue & $\begin{array}{l}\text { Most farmers }(83 \%) \text { leave crop residue on the farm on purpose. The farmers understood that the } \\
\text { residue increases soil fertility and they had been benefiting from this practice. }\end{array}$ \\
\hline Xugessi & $\begin{array}{l}\text { Soil burning, Grass / } \\
\text { bush burning }\end{array}$ & $\begin{array}{l}\text { Practiced by few farmers }(10 \%) \text {. It was usually done during dry seasons. The burning clears the land } \\
\text { and the fire reaches the mountainous places that are difficult to reach. It also eliminates ticks and } \\
\text { weeds. }\end{array}$ \\
\hline Mitisa Tossa & Tree planting & $\begin{array}{l}\text { Practice of planting trees near their farm as fence and boundary demarcation. Example: } \\
\text { Moringaolifera is used for this purpose }\end{array}$ \\
\hline Xinkata Tokessi & $\begin{array}{l}\text { Indigenous grass } \\
\text { planting }\end{array}$ & $\begin{array}{l}\text { Grass planting was promoted as there had been shortage of animal fodders in the area. The farmers } \\
\text { use it at the edge of the farm for protection of erosion and fencing the crops. For example: Elephant } \\
\text { grass are used for this purpose. }\end{array}$ \\
\hline Kelha Kello & Stone band & It was used for catching fertile top soils. \\
\hline Mitisa Tokessa & Vegetation strip & The community used concept of vegetation strip, traditional terracing, and ditches making like that \\
\hline Kasse Gosha & $\begin{array}{l}\text { Traditional terracing } \\
\text { on farm land }\end{array}$ & $\begin{array}{l}\text { of the Konso people. The water shade management of the government program supports this } \\
\text { practice. Strip cropping practiced where strips of two or more crops are alternately placed on the }\end{array}$ \\
\hline Boye Kesso & Traditional ditches & contour for erosion control. \\
\hline $\begin{array}{l}\text { Hixa / Mettaa melena } \\
\text { mala oso }\end{array}$ & Mulching & $\begin{array}{l}\text { Mulching is the covering of the soil with crop residues such as straw, maize or sorghum stalks or } \\
\text { standing stubble. The cover protects the soil from raindrop impact and reduces the velocity of } \\
\text { runoff. However, it was less practiced by the farmers }(5 \%) \text { because of shortage of fodders for } \\
\text { animals. }\end{array}$ \\
\hline Lamessi Lamesssizerre & Crop rotation & $\begin{array}{l}\text { This was used for growing different crops one after another on the same piece of land, season after } \\
\text { season or year after year. It was usual practice and the farmers are aware of the advantage. } 80 \% \text { of } \\
\text { the farmers used crop rotation. }\end{array}$ \\
\hline Walaketiszarre & Intercropping & It was a practice of growing two or more crops at the same time on the same piece of land. \\
\hline Bonchettidayiabottaa & $\begin{array}{l}\text { Existence of conserved } \\
\text { area }\end{array}$ & $\begin{array}{l}\text { Conserved forest and enclosures place were common for creating grazing land and it is being } \\
\text { practiced because of the awareness by government on water shade management program. }\end{array}$ \\
\hline Bonchettidayiamitisa & $\begin{array}{l}\text { Especial culture of } \\
\text { protecting (NRM) like } \\
\text { forest }\end{array}$ & $\begin{array}{l}\text { The areas were culturally protected and conserved for forests by the community mainly because of } \\
\text { spiritual and cultural values. }\end{array}$ \\
\hline Zummaakellaa & $\begin{array}{l}\text { Terracing/contour } \\
\text { making on } \\
\text { mountainous area }\end{array}$ & $\begin{array}{l}\text { Contour cultivation and planting was a practice of plowing land and planting crops along a contour } \\
\text { line. The community does have the concept of terracing like that of the Konso people. The water } \\
\text { shade management of the government program supports this practice and it is creating awareness on } \\
\text { soil and water conservation }\end{array}$ \\
\hline $\begin{array}{l}\text { Watha Gosha / } \\
\text { Dummadummaakatha } \\
\text { Ayafetannemithaissibolla } \\
\text { zero }\end{array}$ & Agro-forestry practice & $\begin{array}{l}\text { It was not providing shade that would affect the field crops. The trees may be either fruit trees or } \\
\text { trees, which have the ability to trap nitrogen from the atmosphere and return it to the soil where it } \\
\text { can be used by other plants. Knowing this fact, farmers commonly practiced it. }\end{array}$ \\
\hline $\begin{array}{l}\text { Hayi ode bitanne hatha } \\
\text { Naagoo }\end{array}$ & $\begin{array}{l}\text { Indigenous soil and } \\
\text { water conservation }\end{array}$ & $\begin{array}{l}\text { This was a farming practices that have evolved through the course of time without any known } \\
\text { outside institutional interventions and the community is partly implementing it mainly in small scale } \\
\text { (on their farm) }\end{array}$ \\
\hline
\end{tabular}




\subsection{Indigenous Practices in the Local Area Development Program}

$75 \%$ of the respondents mentioned that the community does not use indigenous practices for their area development program and natural resources management. Different challenges observed as barriers in implementing indigenous knowledge for natural resource management in the area development program of the study area (Table 2).

Table 2. Barriers in implementing indigenous knowledge for natural resource management in the area development program.

\begin{tabular}{|c|c|c|}
\hline Major Criteria & Observed Result & $\begin{array}{l}\text { Respondent } \\
\text { Rate in\% }\end{array}$ \\
\hline NRM status over the past two decades & $\begin{array}{l}\text { Sharp deterioration with slight increase in recent years. Afforestion, soil and water } \\
\text { conservation programs were not practiced for the past } 15 \text { years but now watershed program is } \\
\text { practiced by government supported by safety net program. Only } 20 \% \text { of the respondent agreed } \\
\text { that NRM is in good status }\end{array}$ & 80 \\
\hline Integrity of IK holders & Poor integrity and unity. Only $23 \%$ respondent expressed that there was integrity and unity. & 77 \\
\hline $\begin{array}{l}\text { Participation level of IK holders in } \\
\text { decision making }\end{array}$ & Low participation. Only $23 \%$ respondent expressed that there was interactive participation & 77 \\
\hline Support for IK sustainability & Insufficient support existed but $25 \%$ of the respondent disagreed with this idea & 75 \\
\hline $\begin{array}{l}\text { Organizing IK holders and institutions } \\
\text { that support Indigenous practices }\end{array}$ & $\begin{array}{l}\text { few are organized but } 25 \% \text { of the respondent agreed that there was activities of organizing IK } \\
\text { holders }\end{array}$ & 75 \\
\hline $\begin{array}{l}\text { Consultation with IK holders in } \\
\text { designing NRM intervention and projects }\end{array}$ & $\begin{array}{l}\text { There were no in-depth discussion or consultation but } 24 \% \text { of the respondent agreed that there } \\
\text { was consultation. }\end{array}$ & 76 \\
\hline Lack of resources and frame work for IK & $\begin{array}{l}\text { Insignificant resources allocation and not clear framework but } 20 \% \text { of the respondent agreed } \\
\text { that IK frame work and resources existed. }\end{array}$ & 80 \\
\hline
\end{tabular}

\subsection{Local Knowledge in Disaster Risk Reduction and Conflict Resolutions}

$86 \%$ of the respondents mentioned that when it occurs, appeal for aid first goes to the government; however, $11 \%$ of the respondents believed that local capacity and their indigenous knowledge is used for immediate remedies. Still $2 \%$ of the respondents agreed that appeal would be forwarded to the neighboring community for support. According to the respondents, commonly occurring disasters in the kebeles are: flood, land slide and drought.

Thus, $90 \%$ of the respondent agreed that there were event of disaster for the past two years in the kebeles. As the focused group discussion revealed, when disaster happens, the most vulnerable groups of community are children, elders and mothers. In the community, there are traditional conflict resolution methods. $80 \%$ of the respondents agreed that traditional conflict resolution methods are practiced by the communities which are mainly lead by elders and reputable ethnic leaders. Soon after the conflict occurs in the communities and between neighboring communities, the Gantacommunity hasits own traditions to solve the conflict. The king is responsible to solve the conflicts. He is expected to give the last decision on social disputes and conflicts at "Dubusha", the traditional assembly place. There are politically well organized structures in the community (Figure 2). The king 'ka'o' is the last decision maker. The "Ogade" implements the decision made by the "ka'o" king and make cultural blessings. The Daana/Alekais somebody with good status of wealth and elected by the community to solve societal crisis including conflict. If 'Daana' is not able to manage the social crises like drought, conflict, and some other natural disasters, the authority will be taken. "Bitaanee" is the responsible body for facilitating trust and unity in the community.

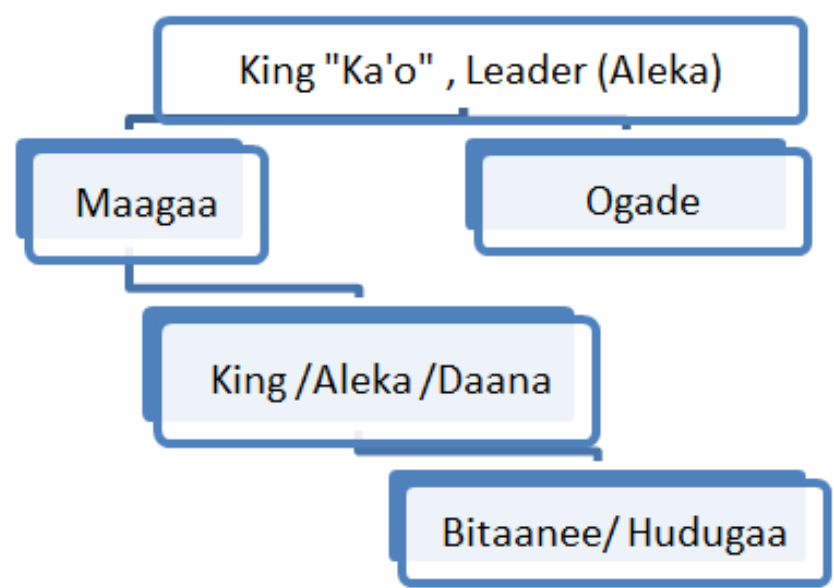

Figure 2. Traditional hierarchal structure in Ganta community.

\section{Discussion}

\subsection{The Role of Indigenous Knowledge in Managing Natural Resources}

Indigenous knowledge is directly tied to the sustainable use and maintenance of a healthy and vibrant ecosystem. Many successful examples of regenerating ecosystems and supporting local livelihoods are found in Zigity kebeles where users themselves have established a management structure, and the management is based upon an indigenous system. A number of indigenous practices contribute to improved nutrient levels and physical soil properties that provide better aeration, infiltration, water holding capacity, and soil moisture (Herweg, 2002). Indigenous agricultural practices indicated in the present studyhave revealed the long enough existence of indigenous practices in the Ganta community. Use of manure for soil fertility is the most 
common agricultural practice in the area. Compost making for soil health is also practiced; hence, decomposed leaves and animal manure are left to ferment and decay near homestead and then transported to farm lands where productivity has decreased. Crop leaves and residues after harvest intentionally left on the farm lands to increase the fertility of the soil for the next crop season.

The severity of soil erosion in the Zigitykebeles is the result of the mountainous and hilly topography, torrential rainfall, and low degree of vegetation cover. From physical observation made during data collection, it was practical that most mountains had low vegetation cover.

Soil burning is less commonly practiced by the community. Use of fire as an ecosystem management tool is an example of one of the oldest applications of indigenous practices which illustrate the potential for indigenous knowledge to influence changes in public land management processes like in range land. Euro-Americans arrived in North America bearing their folk knowledge that held fire in forests to be destructive and hazardous to humans (Arno, 1985; Lewis, 1982). This view contrasted sharply with the traditional knowledge of the indigenous inhabitants, who embraced the benefits of burning and were skilled in application of fire technology (Kimmerer and Lake, 2001).

Although mulching has tremendous advantage for soil health, the practice is less exercised in Ganta community. According to Hobbs et al (2007), mulch resulting from leftover residues is a key component of conservation agriculture that helps promote more stable soil aggregates as a result of increased microbial activity and better soil surface protection. Moreover, it is protective to soil cover shielding the soil surface from heat, wind and rain, keeps the soil colour and reduces moisture losses by evaporation. In drier conditions, it reduces crop water requirements, and makes better use of soil water. Farmers in the present study area are also believed that mulching reduces infiltration.

Tree planting near the farm and in the communal forest areas is practiced in the study area. The agro-forestry activities among which Ensent (false banana), Coffee, Avocado tree, Bamboo, and Juniperus are common plants. The plants have no competitive nature. Different species of: Acacia, Eucalyptus, Juniperus, are also found in the homestead of farmers. The community valued the trees because it serves for food, fuel, medical purpose and other ecological services. For instance the leaf/flower part ofHageniaabyssinica (Kossozhaf) is believed to have healing effect for intestinal worms (Tape worm), underground corm of Enset is also used to repair broken-limbs. Grass planting is also commonly practiced by the community. It is widely used for animals feed. Selected varieties of grass fodders (alfalfa and elephant grass) are introduced for solving fodders scarcities. Crops residues on farmlands are also used for animals' fodder.

Ethiopian farmers have long been aware of the problems of soil degradation and have traditionally developed remedies at farm the level. As soil conservation practice, stone bands are used in the area. The community have the concept of vegetation strip, traditional terracing, and ditches. The water shade management of the government program supports this practice and the farmers are contributed their indigenous knowledge for soil and water conservation measures. However, an extensive work on indigenous knowledge in land management by Kruger et al (1996) showed that there is poor record and lack of appreciation of indigenous practices by soil conservation experts and policy makers. Similarly, study by Reij (1991) showed the less attention given to indigenous soil and water conservation practices by researchers and development agents in Ethiopia.

According to the local farmers, the major annual growing crops are: Maize, Sorghum, Teff, Wheat, Barely, Haricot bean, Irish potato, Sweet potato, and Cassava. Crop rotation is used by the farmers and they understood the nitrogen fixation capacity of leguminous plants. Farmers explained that farming similar crop year after year decreases the crop production. During crop rotation, crops like Wheat or Barley are followed by sorghum intercropping with ka'o pea or horse beans. Maize is intercropped with Haricot Beans and Teff with Sun flower. The fodder plants and grass are used near the farm land as fencing and erosion protection structure. It is a long year's farmer's experiences in which legume crops are rotated with other non-leguminous crops for the main purposes of soil fertility improvement in the study areas The use of crop rotation helps to increase soil organic matter, reduce erosion and bring biological diversity back to the soil (Atakilte, 2003).

Intercropping follows specific arrangements where some legume animal fodder and haricot bean grown in rows within the main crops (maize and sorghum) in the study area. The farmers' practices intercropping mainly to ensure the availability of food from different crops and to obtain animal feed on continuous supply. At the same time this practice also improves soil fertility through crop diversification and provides soil cover to protect the impact of rain drop on soil and minimize erosion (Abebe et al., 2011).

Culturally protected areas, such as, conserved forest and enclosure places are common in the study area. Especial culture of protecting forest is maintained by spiritual leaders. In spite of availability of documents on indigenous practices, little evidence exists on promotion of the indigenous practices for better use, systematic conservation to increase the natural resources management and in modern development effort.

The indigenous practices in the long run contributes to improving soil ecological functions (productive, supportive, regulation and recreational). In spite of variation from farmer to farmer, a different indigenous practice of land management contributes to different degree of accumulation of organic matter over time contributing to better natural resources. On the basis of the features of indigenous land management and significance of the practices from point of natural resources management, improving soil ecological function is observed in the study area (Table 1). Indigenous practices are important for currently deteriorating environment and natural resources management. Indigenous 
technologies are developed by local community to solve a particular problem (Ajibade, 2003). In one way or the other soil ecological services are improved by indigenous practices although there is variation in the type of service to be enhanced. Indigenous agro forestry and crop rotation and mulch are used as coping mechanism for drought, minimize effect of disease and has role in climate change adaptation (Abebe et al., 2011).

In the present study, majority of the respondents $(82 \%)$ have confirmed that land degradation is a serious problem in the 'kebeles'. It is a result of several factors of both physical and socio-economic nature, and also major cause of poverty in rural areas of developing countries. In Zigity kebeles, the community experienced productivity decline due to demographic, economic, social, and environmental changes/factors. The immediate repercussion of land degradation is reduced crop yield followed by economic decline and social stress. According to Greenland et al., (1994) integrated process of land degradation and increased poverty has been referred to as the "downhill spiral of unsustainability" leading to the "poverty trap".

Soil erosion is severe in Zigity kebeles and posed a major threat to continue in declining of agricultural productivity in the area. Virtually, all topsoil, and in some places parts of the subsoil, has been removed from sloping land leaving stones or bare rock at the surface. Continues and extensive uses of chemical fertilizers is practiced by the farmers, whereas the custom of using organic fertilizers is scanty.

Generally, the local farmers and the extent to which local knowledge practices used by farmers have to be lifted-up promoted and encouraged by policy makers and development actors. Above all, the government natural resources management session should give attention for local knowledge for the best use of natural resources in the stud area.

\subsection{Indigenous Practices in the Local Area Development Program}

Traditional ecological knowledge is the primary indigenous way of understanding relationships among species, ecosystems, and ecological processes. Traditional ecological knowledge has the potential to play a vital role in climate change assessment and adaptation efforts that bridge human and environmental systems. Not only does it hold relevance for indigenous groups, but it is also being recognized as an invaluable contribution to the larger climate change discussions occurring at regional, national, and international levels (Parrotta and Agnoletti, 2012). According to focused group discussion made with elders of Ganta community on natural resources management, the status over the past two decades showed declining trend. Presumably, this is due to the interplay of social, economical and cultural factors.

Traditional ecological knowledge is acknowledged as having fundamental importance in the management of local resources, in the husbanding of the world's biodiversity, and in providing locally valid models for sustainable living"
(Turner and Clifton, 2009). The integrity among indigenous knowledge holders was poor and their participation had been low in their area development programs. This was also proved with the fact that traditional knowledge is not consulted with indigenous knowledge holders in designing natural resources management intervention and projects. Support and organizing of indigenous knowledge holders and its continuity was insufficient. There was lack of resources and frame work for indigenous practice. Some countries are aware of this limitation and they put indigenous knowledge to be considered in their policy designing. It is a policy in Canada that traditional ecological knowledge (TEK) be considered and incorporated into resource management (Usher, 2000). Traditional ecological knowledge can include diverse kinds of observations by an indigenous person or group (Menzies and Butler, 2006). These narratives, in turn, can provide intergenerational observations of various kinds of natural resource phenomena (Alexander et al., 2011). Natural resources management is more sustainable when beneficiaries engage in managing resources and maintaining structures. Strong local institutions are a prerequisite for equitable natural resources management, and in many cases the most successful interventions involve community organizations such as water users' associations. In building on existing formal or informal community groups, it is crucial to ensure that the poorest and most vulnerable, particularly women, are included and have an opportunity to participate in community decision-making processes.

Community consultation for commencing natural resources management intervention in the early stages of a plan and the indigenous practices used in area development program in designing natural resources management strategy of the community have showed low correlation in the present study. Likewise, $82 \%$ of the respondents reflected that very minimal concern is given to community consultation. The involvement of traditional authorities in the formulation of natural resources management policies at the planning stage, monitoring and evaluation stages is found to be low.

According to Benjamin (2016), empowerment and support to indigenous or local communities that choose to develop their own programs for managing and recovering rare species in their homelands and waters as a means to maintain or revitalize culture and customs has the capability to sustain traditional livelihoods. The policy makers however, encounter some constrains in the implementation and dissemination of the policies and program plans. These are indicated as: the integration of modern and traditional management practices; the lack of funds to carry out education on the policies; inadequate apprehension of policy documents and social ties as a constraint in implementing community guidelines for managing community natural resources. Therefore, this suggests that, traditional institutions and systems into natural resources management lack the necessary capacity and resources for policy implementation, accounting for resistance in policy reforms in the district in some instances due to attitudes, values and practices that might not be taking into consideration at the 
planning stages. Local management by those who are familiar with the ecosystem and have a personal interest in the well-being of the natural resources appears to be the most effective procedure for conservation and sustainable development in developing countries (Watson et al., 1998).

The indigenous practices in the local area development program are not fully utilized due to several reasons that are interwoven among which low education level, low awareness by the development workers and lack of frame work for the indigenous knowledge holders to participate in the natural resources management. Despite the less concern given by the area development practitioners, community practices have remained an important asset of the community to manage the ecosystem. Local knowledge contributes a lot for maintaining the degraded natural resources. Efforts to use indigenous knowledge technologies (IKT) for efficient utilization of natural resources, and protection of environment are still issues to be addressed as gaps in future (Abebe et al., 2011).

The 2008 United Nations Declaration on the Rights of Indigenous Peoples addresses the indigenous right to control and protect traditional practices in article 31, which states: Indigenous peoples have the right to maintain, control, protect and develop their cultural heritage, traditional knowledge and traditional cultural expressions, as well as the manifestations of their sciences, technologies and cultures, including human and genetic resources, seeds, medicines, knowledge of the properties of fauna and flora, oral traditions, literatures, designs, sports and traditional games and visual and performing arts. They also have the right to maintain, control, protect and develop their intellectual property over such cultural heritage, traditional knowledge, and traditional cultural expressions (United Nations, 2008).

\subsection{Local Knowledge in Disaster Risk Reduction and Conflict Resolutions}

Natural disasters are often amplified because of poor natural resources management. In the present study, $86 \%$ of the respondents revealed that the community capacity to engage in disaster reduction activities is low, as they always seek help from the government. Many of the recent disasters have demonstrated the failure of the system to support affected communities, making people helpless and causing greater damage. Therefore, an ideal disaster reduction measure should incorporate a balanced mix of modern technology and traditional knowledge (Nakano et al., 1974). Threats to ecological systems due to destruction of habitats, introduction and loss of species are the most serious environmental problems in Ethiopia. In a country endowed with such biological diversity, diverse ecosystem and over 80 ethnic groups, indigenous knowledge has contributed a lot for maintenance of present day ecological bio-diversity against the past natural and social disaster (Abebe et al., 2011).

Concerning conflict resolution, when it occurs within the community and between neighbouring communities, the Gantacommunity have their own traditions way to resolve the conflict. Pursuant to the cultural law, the traditional institutions have a role to pass the verdict. These collective actions in natural resource management are expressed through religious believes, moral sanctions and a range of sacred and cultural practices. The king 'ka'o' is the last decision maker; he/she solves the social problems in the community and with the neighbouring community. The "Ogade" implements the decision made by the "ka'o" king and make cultural blessings. The Daanaa /Alekais somebody with good status of wealth and elected by the community.

At 'Dubush' the traditional assembly place, he/she will be appointed by the community for the position. This shows that the community has the culture of exercising democratic election and self-empowering. The Daanaa /Aleka term of service is for two years. Daanaa's wife has also get good prestige in the community. If 'Daanaa' is not able to manage the social crises like drought, conflict, and some natural disasters, his term will be terminated and others in the structure will take over the duties until next Daanaa appointed by the community.

"Bitaanee" is the responsible individual for facilitating trust and unity. $\mathrm{He} / \mathrm{she}$ is also responsible to carry out cultural ceremony. 'Maagaa' is responsible for spiritual and ritual ceremony leading traditional believes. The "Maagaas" make sure that cemetery areas are not open lands but covered by forest. The trees in such place are never being cut. The natural resources management strategy has advantage to consult such resourceful individuals for afforesting and forest management program of the area. "Damusa" is somebody who is believed to have spiritual power and work with "Bitaanee". He /she is responsible to select sacred forests. Because of spiritual reasons the hair of 'Damusa' will not be trimmed throughout his/her life, so does the sacred forests he/she manages. If somebody cuts a tree from the forest he /she will be cursed and therefore, the ceremony of cleanliness and repentance has to be organized. The "Damusa" pleads God 'Tossoo' to bless and cures somebody and God hears. In some parts of Africa, natural resources are the very basis of religion and cultural beliefs, therefore, certain areas such as woodlands, water points, mountains etc. are considered to be sacred (Paula, 2004).

Ogade /carre/ Gana plays the role of communication, mediation and counselling. The Ogade are responsible to resolve and deal if there are social problems concerning pasture, water, and boundary. He / she is with high skill of cultural knowledge and has to be good orator.

Exploitation of the natural resource base was systematic and could only be done through the inspiration of spirit mediums and through the guidance of traditional institutions for the benefits of the whole Community (Paula, 2004).

Generally, these traditional administrative structures are very important to manage the natural resources in the study area. Public participation at all stages is vital for natural resources conservation. The Ganta communities have a diverse knowledge on disaster mitigation based on traditionalwisdom. Since they live in remote, isolated and inaccessible hamlets on the ridges or on the foothills, they 
have their own coping strategies in times of disaster. Crossfertilization and blending of thisindigenous knowledge with modern scientific knowledge could strengthen the communities' capacityin disaster mitigation and preparedness. Detailed, systematic and intensive studies on indigenousknowledge would contribute to a more comprehensive understanding and appreciation of their overallcontribution for better and safer living conditions of the people. It is therefore highly imperativeto collect, compile and systematize the diverse range of indigenous knowledge before it disappears. A record of such knowledge will show if more can be done to make the efforts of building disastermanagement capacity in the communities not only cost-effective but also sustainable and harmonious tothe nature-culture interface. Indigenous-led social institutions provide the means by which societies can act on their local knowledge to support livelihoods based on the environment (Benjamin, 2016).

Environment and disasters are inherently linked because of the strong dependency and interconnectedness of natural resources with the environment. Deforestation, degradation of catchments/watersheds, degradation of land and desertification, among other factors, reduce nature's defence capacity against hazards and aggravate the impact of disasters such as floods, landslides, and drought. Disasters in turn contribute to ecosystem degradation and loss, including increased soil erosion, declining rangeland quality, salinization of soils, and biodiversity loss. Increasing environmental degradation reduces the availability of goods and services to local communities, shrinks economic opportunities and livelihood options, and ultimately contributes to greater food insecurity and hunger. It further drives increasing numbers of people to marginal lands and fragile environments (Benjamin, 2016).

\section{Conclusion}

Traditional ecological knowledge has the potential to play a vital role in natural resources management and the contributions to climate change efforts with local institutions, and government organizations at local, woreda and zone levels is substantial. The wealth of indigenous practices in land management in Ganta community is reflected in the diversity of practices, terminology used and existence of indigenous land-use classification. There are socio-economic factors negatively influencing indigenous practices that contribute to fragility of ecosystem. The existence of hindrance factor reflects the reduced capacity of the knowledge system and less consideration of the indigenous knowledge holders to contribute in sustaining ecosystem. Indigenous practices system is important to maintain the present day diverse and rich natural resources among the Ganta community in the kebeles. The effort to promote, develop, conserve and use indigenous practices in greater scale is at early stage. Lack of formal education and capacity building for better use of local knowledge and natural resources management has negatively affected the development program of the area. Full participation of indigenous knowledge holders on local natural resources management has paramount role for maintenance of indigenous practices and they share skills and knowledge to the community while participating on communal development activities. Ganta community has indigenous knowledge of well-structured socio political system of transferring social power without conflict and it is inbuilt peaceful democratic social system that came through culture.

\section{Acknowledgements}

We are grateful to Arba Minch Zuria Woreda Administration Office for providing valuable information and unreserved cooperation. Further, we are very thankful to Arba Minch University for covering all financial expenses.

\section{References}

[1] Abebe, S. Hans, H. Getez, Z and Berhanu, D. (2011). Indigenous Knowlage in Land Management for Sequestration and Soil Based Ecological Services in Damot Sore (Wolayta), Southern Ethiopia, A Report Submitted to international start secretariat. (Report No 3).

[2] Alexander, C., Bynum, N., Johnson, E., King, U., Mustonen, T., Neofotis, P. et. al., (2011). Linking indigenous and scientific knowledge of climate change. Bio Science. 61 (6): 477-484.

[3] Atakilte, B. (2003). Soil conservation, land use and property right in northern Ethiopia. Understanding environmental change in smallholder farming systems. Doctoral Thesis, University of Bern, and Swiss National Centre of Competence in Research (NCCR) North-South (Unpublished).

[4] Arba Minch Zuria Woreda Administration Office (2015). Annual Woreda Reports, Arba Minch Town.

[5] Arno, S. F. (1985). Ecological effects and management implications of Indian fires. In: Proceedings: symposium and workshop on wilderness fire. Gen. Tech. Rep. INT-182. Ogden, UT: U.S. Department of Agriculture, Forest Service, Intermountain Forest and Range Experiment Station: 302-303.

[6] Ajibade, L. T (2003). A Methodology for the Collection and Evaluation of Farmers' Indigenous Environmental Knowledge in Developing Countries, INDILINGA African Journal of Indigenous Knowledge System, 2: 99- 113.

[7] Benjamin, $T$ (2016). Passing on a sense of place and traditional ecological knowledge between generations. In: The Future of Ethnobiology: Linking Cultural and Ecological Diversity. Nabhan G. P (Ed.). University of Arizona Press.

[8] Brussel SEC (2009). Adapting to climate changes: the challenge for European agriculture and rural areas. Commission of the European communities. Commission working staff working document accompanying the white paper No. 147.

[9] CSA (2016) National Statistical Abstracts, http://www.csa.gov.et/doucments/National Abstract Statistics/2016 national statistics (Abstract). 
[10] Greenland, D. J., Bowen, G. Eswaran, H. Rhoades, R. and Valentin. C. (1994). Soil, water, and nutrient management research - a new agenda. IBSRAM Position Paper, International Board for Soil Research and Management (IBSRAM), Bangkok, Thailand.

[11] Herweg, K. (2002). Indigenous soil management, In; Encyclopedia of Soil Science Lal, R.(Ed.), pp 679-682, Marcel Dekker, Inc, New York.

[12] Hobbs, P. R., Sayre, K., Gupta, R., (2007). The role of conservation agriculture in sustainable agriculture. Philosophical Transactions of the Royal Society of London 363: 543-555.

[13] Kimmerer, R. W. and Lake, F. (2001). The role of indigenous burning in land management. Journal of Forestry. 99 (11): $36-41$.

[14] Kolawole, O. D. (2001). Local Knowledge Utilization and Sustainable Development in $21^{\text {st }}$ Century, Indigenous Knowledge and Development Monitor 4 (3): Page No 9.

[15] Kruger, H. J., Berhanu F., Gebere Michael Y., and Kejela, K (1996) Inventory of indigenous soil and water conservation measures on selected sites in Ethiopian Highlands. Soil Conservation Research Report 34. Centre for Development and Environment (CDE), University of Bern, Switzerland.

[16] Lewis, H. T. (1982). Fire technology and resource management in aboriginal North America and Australia. In: Resource managers: North American and Australian hunter and gatherers. Williams, N. M., and Hunn, E. S., (Eds.) American Association for the Advancement of Science Selected Symposium Series No. 67. Boulder, OR: Westview Press: 45-67.

[17] Liniger, H. P. and Critchley, W. (2007). Where the land is greener: case studies and analysis of soil and water conservation initiatives worldwide, World Overview of Conservation Approaches and Technologies (WOCAT), Joint publication of CTA FAO, UNEP, CDE, $376 \mathrm{pp}$.

[18] Menzies, C. R. and Butler, C. (2006). Introduction: understanding ecological knowledge. In: Traditional ecological knowledge and natural resource management. Menzies, C. R., (Ed.) Lincoln, NB: University of Nebraska Press: $1-17$.

[19] Nakano, T., Kadomura, H. Mizutani, T. Okuda, M. and Sekiguchi, T. (1974). Natural hazards: Report from Japan. In: Natural Hazards: Local, National, Global White, G. and Burton, I. (Eds.). Oxford: Oxford University Press. 231-245.

[20] Parrotta, J. A. and Agnoletti, M. (2012). Traditional forestrelated knowledge and climate change. In: Traditional forest- related knowledge: sustaining communities, ecosystems and biocultural diversity. Parrotta, J. A. and Trosper, R. L. (Eds Dordrecht, The Netherlands: Springer: 491-534.

[21] Paula, D. (2004). Indigenous Knowledge Systems in subSaharan Africa: An Over view. Indigenous Knowledge, Local Pathway to Global Development, the World Bank, African Region. pp 36-38.

[22] Reij, C. (1991). Indigenous Soil and Water Conservation in Africa, Gatekeeper Series No.27, pp 35, IIED, London.http://www.iiav.nl/epublications/1991/indigenous_soi 1_and_water_conservation_in_africa.pdf.

[23] Reijntjes C. (2004). Bridging local knowledge and global science, COMPAS Magazine, pp 41-43.

[24] Rist, S. and Dahdouh-Guebas, F. (2006). Ethno sciences- a step towards the integration of scientific and indigenous forms of knowledge in the management of natural resources for the future Environment Development and Sustainability, 8: 467493.

[25] Thrupp, L. A. (1998). "Legitimizing Local Knowledge: From Displacement to Empowerment for Third World People". Agriculture and HumanValues. Summer Issue. pp. 13-24.

[26] Tripathi, N. and Bhattarya, S. (2004). Integrating Indigenous and GIS for participatory Natural Resource Management. State of the practice The Electronic Journal of Information Systems in Developing Countries 17 (3):1-13.

[27] Roscoe, J. T. (1975) Fundamental Research Statistics for the Behavioural Sciences, 2nd edition. New York: Holt Rinehart \& Winston.

[28] Turner, N. J. and Clifton, H. (2009). "It's so different today": climate change and indigenous life ways in British Columbia, Canada. Global Environmental Change-Human and Policy Dimensions. 19 (2): 180-190.

[29] UNEP. (2008). Indigenous Knowledge in Disaster Management in Africa, Nairobi, Kenya, 108 pp.

[30] Usher, P. (2000). Traditional ecological knowledge in environmental assessment and management. Arctic 53: 83-93.

[31] Warren, D. M., and Rajasekaran, B. (1993). Putting Local Knowledge to Good Use, International Agricultural Development 13; 8-10.

[32] Watson, R. T., Kalala, M., Lachance, A. andMartella, G. (1998). Protecting Our Planet, Securing Our Future: Linkages Among Global Environmental Issues and Human Needs. Washington, D. C.: United Nations Environment Program, U.S. National Aeronautics and Space Administration, World Bank. 